\title{
Magnus Lawrie
}

\section{TRASH VERSIONALITY FOR POST-DIGITAL CULTURE}

APRJA Volume 3, Issue 1, 2014

ISSN 2245-7755

CC license: 'Attribution-NonCommercial-ShareAlike'. 


\section{Media Trash}

\section{RHETORIC}

Following a 14-day visit to parts of the UK, the United Nations' special rapporteur on adequate housing Raquel Rolnik, issued an end-of mission press statement.[1] She recommended immediate suspension of controversial reforms affecting social housing tenants.[2] Researched according to UN protocol (Gentleman), the advice was however vehemently rejected by the UK government; the rapporteur's personal and professional credibility were then attacked in the media and elsewhere.[3]

These changing dynamics, between public and political spheres are especially visible online, where social media is influencing many areas. In one instance a court trial was abandoned after new evidence, obtained from a disused Twitter account, came to light. Details of the accused were nevertheless reported in print and on the Web.[4] Elsewhere, legal proceedings have been derailed because of jurors' activity online (Davis). Incautious tweets have resulted in prosecutions for libel (BBC News).

This article attempts an overview of phenomena, which exemplify informational and conceptual instances (or 'versions') characteristic of current 'post-digital' conditions. By counter-posing a variety of material, I aim to explore the role and position of different kinds of images (foremost social and visual) as they constitute post-digital relations. These are relations in which the primacy of computerized digital objects is moot. The versions presented in this text are the social, cultural and organizational confluences which find expression in differing data formats - originals and copies subject to fluctuating, moment-to-moment alteration. Together with the growth in communication and exchange, these versions imply a continual re-writing of the standards affecting social and network-based encounter. The processes renew shared conceptions and pictures, prompt self-reflection and pose the questions, "whose truth?" and, "whose value(s)?".

\section{INDISPENSABILITY}

As quickly as attention has switched away from the aforementioned episodes, they offer us a snapshot of a media landscape in which trash, as dispensable news and information, is merging with public opinion and political rhetoric. The combination of booming mass culture and creativity produces a variety of images — including data images — which are not easily locatable within the apparatus' of political, social and economic assemblages. Consequently, these images (whether personal or institutional) are open to conjecture. Their position on the continuum between media, platform and network transport renders them equivocal - ambiguous entities, where identity, trust and authenticity come under review.

These are issues which are problematized in an artwork by Kripe, Schraffenberger and Terpstra; The Formamat (2010) investigates the value individuals place on data they have stored on their mobile devices. The work is a vending machine, "which returns candy in exchange for the deletion of [an individual's] digital data". The authors, "invite people to experience the joy of deletion in a public space and encourage them to think about the value and (in-)dispensability of their files while also researching the subject in a broader sense by storing and analysing their deletion-behavior." (Formamat)

\section{REVISION}

With the hindsight of just a few years, The Formamat can also be seen to capture uncertainties - of ownership and identification - in our relationship with data. 
Our understanding of the work encounters an unexpected revision, reformulating the question, not of which, but of whose files are going to be deleted. Taken together with the Internet's long memory - from the Internet Archive's Way Back Machine[5] to playfully macabre, assisted Facebook-identity suicides[6] — this observation underlines the attention now being given to choice and control of data. Here, Nissenbaum's 'contextual integrity' is relevant. It advocates the individual's right to manage the flow of their personal information, rather than exert absolute control (Nissenbaum). The emphasis seems to be on the subjective way we value information, where one person's waste can become another's livelihood.

Such perspectives might be welcomed by the Sunlight Foundation, known for coordinating crowd sourced analysis of US government records. Transparency initiatives like this commonly use Wikis to manage document revisions made by multiple authors (Sifry). In the case of Wikipedia, software for 'version control' becomes the image of a community and its knowledge, a reflection of that community in code:

People can and do trust works produced by people they don't know. The real world is still trying to figure out how Wikipedia works...Open source is produced by people that you can't track down, but you can trust it in very deep ways. People can trust works by people they don't know in this low cost communication environment. (Cunningham qtd in many2many)

\section{VERSION CONTROL}

Other types of version control system (VCS) are useful, especially in co-ordinating software development groups. The Linux kernel project is one example. For this, a very specific VCS was conceived: Git [7] was created to manage all the code for the Linux kernel. It solves problems of ownership and responsibility with its own purpose built command: git-blame.[8] The command finds the author of an edit or addition and reports when changes were made. This is one way in which Git addresses the techno-social problems of making and releasing new versions of the kernel image (the core of the GNU/Linux operating system; a large-scale project with more than nine million lines of code).

The Git software was created with security, authentication and traceability as paramount concerns. Contributors to any Git-maintained project are encouraged to advance development by regularly committing smaller changes into a main line of development. Additions and revisions can be written and tested in isolation before being introduced to the main line or 'branch'. Copies of this branch become distributed as changes are written back to the computers of other developers as they also submit their work. Files 'checked out' from the main development tree can be added to newly created branches. Typically, these development threads are later merged into the project's main branch or abandoned. In some instances, new branches diverge substantially from the main development effort. This is basically the concept of project forking. It might be apparent from this summary that talk about governance in Git is necessarily also a discussion about technical operation.

Issues of governance are also dealt with in creative projects which utilize and discuss version control. Simon Yuill's Social Versioning System [9] and Matthew Fuller and Usman Haque's Urban Versioning System 1.0 [10] concern the relevance of Free Software principles to consensus and co-operation in design practice: 


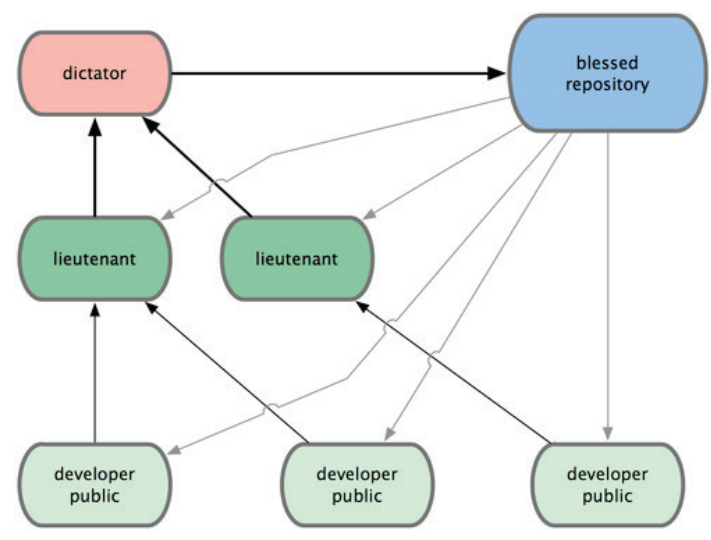

Figure 1: "Benevolent dictator workflow". Illustration. n.d. Distributed-workflows, git-scm.com. Web. 29 Sep. 2013.

one of the most interesting aspects of open source software is the continuous interleaving of production, implementation, usage and repurposing processes, all of which can and sometimes must be open - not just an "open design" that then gets implemented in a closed manner. (Fuller and Haque 17)

Soon after Git was released, GitHub [11] appeared. Using the apparatus (the 'plumbing and porcelain') which comprises the Git software, GitHub establishes a web-based repository for software projects whose source code is released in the public domain. GitHub has been adopted by a huge and rapidly expanding user community, as a platform for developing and publishing software and a range of other creative works. GitHub provides a large-scale, distributed means to recognize and pin point different stages in the production of these works. It has also become home to a mass of never changing, user-generated software configuration files. In GitHub these can be Git configuration files, stored in a Git repository, on a platform built using Git.

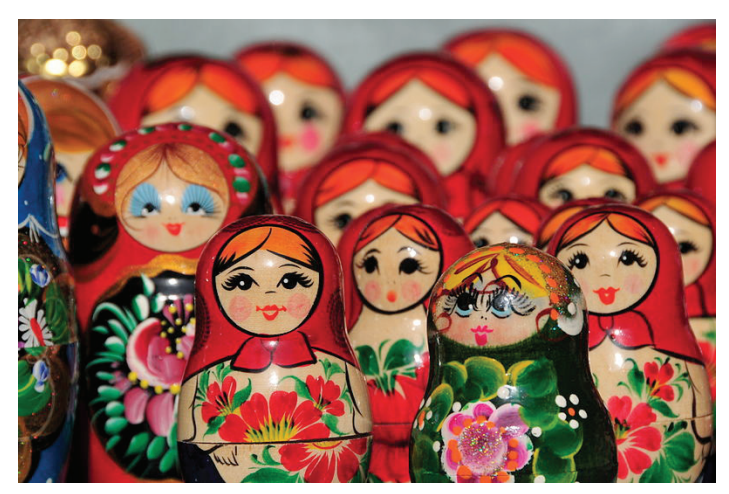

Figure 2: Marcosleal. "Matryoshka dolls in street fair - Budapest". Photograph. 2008. Matryoshka dolls in Budapest.jpg. Wikimedia Commons. Web. 29 Sep. 2013.

\section{Social overload}

\section{ETHICS AND ETIQUETTE}

Besides the sense of community that data sharing in this way inspires, proliferating codes also produce tensions. Where levels of interest from the public increase, the scale and relative value of contributions can in turn challenge a project's direction. WikiLeaks' release in 2010 of hundreds of thousands of classified US Army field reports (the socalled Iraq War Logs) is an example where the relevance and reliability of material have been key considerations (Domscheit-Berg). In other guises, this problem of managing contributions has been encountered in projects from Community Memory (an electronic bulletin board), through to contemporary hacker spaces and Open Source tech communities. In all these instances, it seems that mutual agreement - whether or not this has been explicitly defined - is a central issue. Arguments often focus on leadership, personal style and the possibility of 'benevolent dictatorship' (Lovink). Though positive feedback generated by self-enhancing 'recursive geek publics' is not without drawbacks (Kelty), neither is it clear how this energy can work best - in the case of the Debian 
Software Project there is the Debian Social Contract,[12] enshrining free speech and enough hierarchy to manage the flow of contributions. Free speech has been central to the development of Free-Libre Open Source Software (Turner), as it has to the protocols and conduct written into projects such as Wikipedia.

Away from hacker-styled communities, in observing public sector adoption of open source software, Maha Shaikh explains that, "information technology and users are not defined outside their relationship but in their relational networks". Hence the focus moves away from actors, "towards a more complex, and less defined phenomenon... the interaction". This perspective, emphasizing mutability and becoming is advantageous to understanding materializing of public sector adoption of open source software: "performativity leaves open the possibility of events that might refute, or even happen independently of what humans believe or think". We are presented with a different means to envision interaction, "drawing on ideas of becoming, tracing versus mapping and multiplicity alongside the shared ontology of Actor Network Theory". Shaikh concludes that,

the becoming of adoption can be both constrained and precipitated by various forms of materiality (of the assemblage of the open source ecosystem)... open source software a much touted transparent and open phenomenon - is by its nuanced mutability able to make the process and practices surrounding it less visible. (Shaikh 123-140)

\section{BENEATH THE STREET, THE NETWORK} Conversely, since the release of NSA files by Edward Snowden, meshing and co-dependent network assemblages and apparatus' (as well as the methods by which they constitute one another) have gained visibility. Journalistic reporting of this data at first underlined governments' ability to track and target individuals at will (for example, by following calls and data from mobile phones). Subsequently, attention has moved somewhat away from wireless networks and 'eyes in the sky' to the image of massive submerged and underground data pipes, connecting (really big) data centres routinely serving information to government secret services. Documents detailing these practices provoked strong objections from businesses who insisted on the 'right to reveal'. [13] This twist on the 'right to know' placed mutability and truth centre stage.

Besides this totalizing image of state control and vested corporate interests, is the changing interplay between humans, machines and geography. The activities of Anonymous, and organizations such as WikiLeaks and The Pirate Bay continue to demonstrate the actually fragmented, disorganized and dis-regulated condition of government and businesses, which are not always pulling in the same direction. Meanwhile, activist groups find identities outside of pre-existing ones (of public friend or foe) as their operations compose new and revised networks, in street action, engagement with news media, and in online provocations.

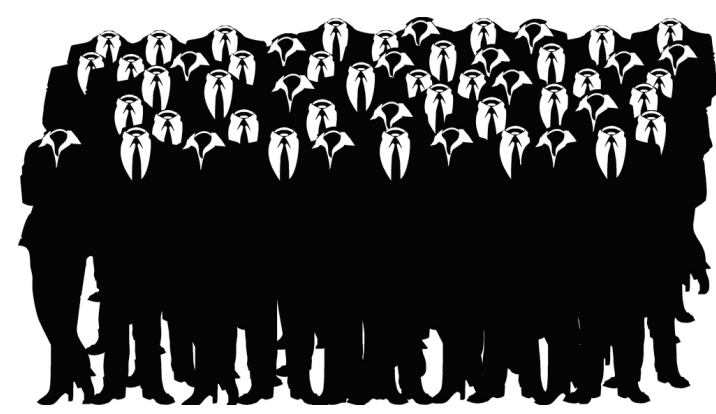

Figure 3: Anon617. "Anonymous Crowd". Illustration. 2008. Anonymous Crowd, flickr.com. Web. 10 Jan. 2014. 
In the encounter between Anonymous and their targets, a firmament of politics and identity shows the interconnectedness of free speech and anonymity. Alternatively, the evidence in revelations about state surveillance precisely demonstrates that anonymity is not an essential aspect of digital networks, but rather is a set of standards which in many places is already compromised. Cloud computing, Software as a Service and skeuomorphic interfaces readily belie the real sense in which data is exposed. With the changed connotations of 'access', Ted Nelson's invocation, 'you must understand computers now' (Nelson) is renewed by under-reporting in the media (Jarvis).

\section{ABUNDANCE AND MODIFICATION}

Anonymous is one contemporary expression of this will to understand computers (as well as other network forms). In a moment of selfreflexive wonder, in February 2008, members of Anonymous turning up for street protests were themselves surprised - in numerous ways - by the people converging on that day, and by the network image this manifestation bodily performed. In one documentary, protesters describe their feelings of being a part of Anonymous and how, as it entered the world, it came to exist in a significantly new way, for them and others. Information activist Barrett Brown explains:

Anonymous is a series of relationships. Hundreds and hundreds of people who are very active in it - who have varying skill sets, and who have varying issues they want to advance - these people are collaborating in different ways each day. (Brown in BBC)

Emerging platforms allow recursive representations of existing creative forms, whilst re-versioned political slogans and insider nods - to Surrealist and Situationist imagery - issue from anonymous channels and deviant locations.[14] These creations, designed for modification, are then absorbed into the melee engaging internet memes and personalities. One notable example of this recursion and modification concerns a prominent UK politician, Ed Balls. In April 2011 he inadvertently tweeted an empty message along with his name. This spawned a long chain of varyingly humorous and teasing responses, facebook likes, as well as many retweets. The action entered meatspace at the time of the original tweet's two year anniversary, when Ed Balls acknowledged the joke by retweeting the following image:

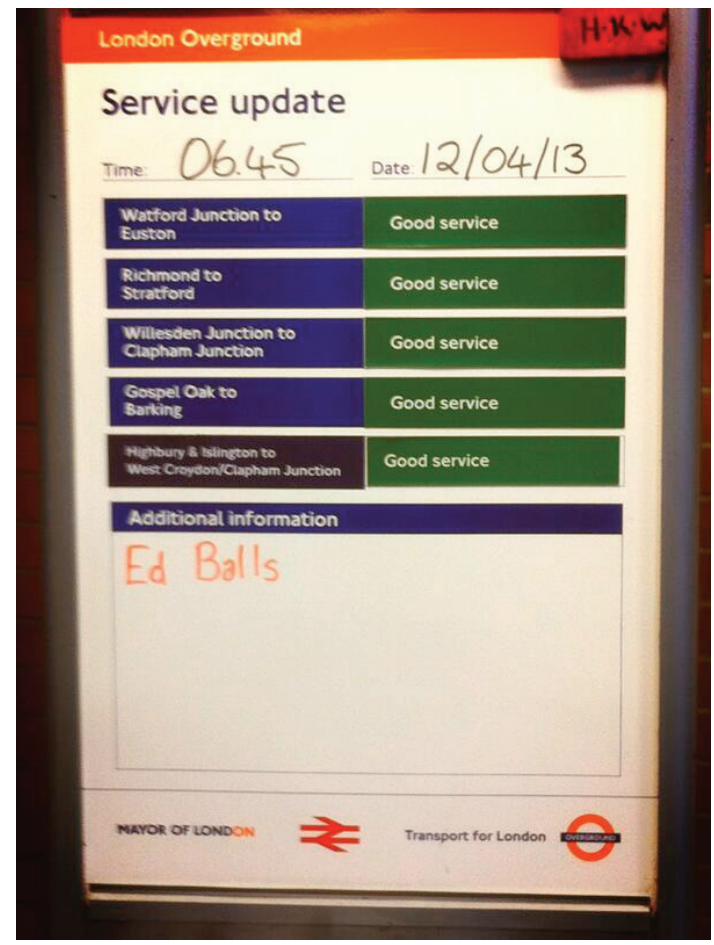

Figure 4: Balls, Ed (edballsmp). "Sorry... But this is getting really weird.. RT @ FelicityMorse: Ed Balls makes it onto a train sign.” 10:01 PM - 12 Apr 2013. Tweet.

\section{REDUCTION AND OVERLOADING}

The impact of flourishing social media (and its reflective potential) receives additional validation through public acquisition of artworks such as The Cybraphon,[15] through 
Wikimedia outreach projects[16] and in metric analysis of the public mood via twitter and the blogosphere.[17] Reflecting this change, networks of users now create, "fast, fluid and innovative projects that outperform those of the largest and best-financed enterprises" (Tapscott and Williams qtd in Heath Cull 78).

The value of such observations was not lost on Julian Assange and Daniel DomscheitBerg as they went about building WikiLeaks. Starting with only minimal funds and relying on their own technical expertise, the two activists would typically exaggerate the scale of WikiLeaks (for example by using fictional identities of people working in purely notional departments). During this time DomscheitBerg used the pseudonym Daniel Schmitt. Assange used his own name, but was occasionally still identified by his old hacker handle of MENDAX (Domscheit-Berg). Alongside this overloading, re-purposing and extension of identity within WikiLeaks, there has been the task of gathering, sifting and reproducing large quantities of data. This was achieved through various means, partnerships and collaborations. However, Domscheit-Berg's subsequent criticism was that WikiLeaks has fundamentally always been a network of one (Domscheit-Berg).

By contrast, Anonymous forms (including memes, reddit and 4chan forums) lend themselves rather less to analysis - their direction being to continually circumvent and override. However, what these forms do present us with, are collaboratively made creative network entities. In the changing dynamic by which these appear, new conventions are being worked out; overloading standards of taste and acceptability are stimulating alternatives to the ordinary narratives of conflict and resolution.

\section{Trash versionality}

\section{DISRUPTIVE CONVERGENCE}

In these forms of representation which we see entering mainstream narratives, a kind of collective and competitive vandalism is esteemed. The multiplicity of voices - for which the expanding net has become more lightning conductor than conduit - increasingly provides its own self-fulfilling cycle of news, serving 24-hour comment and analysis for comment and analysis. A re-writing is under way, in which messages combining text and visual images, produce networks within networks. These communications become the mutable containers of doubt and disinformation, of intent and ignorance:

$$
\begin{aligned}
& \text { since images are two-dimensional the } \\
& \text { representations in them form a circle, } \\
& \text { that is, one draws its meaning from the } \\
& \text { other, which in turn lends its meaning } \\
& \text { to the next. Such a relationship of } \\
& \text { exchangeable meanings is magical. } \\
& \text { (Flusser 9) }
\end{aligned}
$$

\section{DISEASEFUL MEDIA}

From miniature artefacts to large network entities, whether as discrete objects or grand-scale public conceptions, the representations and mental images can seem diffuse, untraceable, and in contradictory states. Nodes, which constitute networks, are themselves potentially networks and networks are collapsible forms, in which processes, "are recurrent [processes]... which typically involve entirely different mechanisms... larger scale assemblages of which some of the members of the original population become component parts." (De Landa 19). Little wonder if the scale and definition of networks should induce feelings of disorientation, even anxiety. 
Magnus Lawrie: TRASH VERSIONALITY...

However, overload also gives rise to easeful interactions. These go against any supposed separation of relations on the Internet and those In Real Life (IRL); In The Pirate Bay: Away From Keyboard (TPB:AFK), Pirate Bay founder Peter Sund explains assuredly to a Swedish courtroom, "We prefer not to use IRL. We believe the internet is for real".[18] Whilst the motivation and affiliations of the the Pirate Bay trio have remained opaque to state and private prosecutors, in this film the question which achieves over-arching significance is, "Who do you trust?". This may be a point around which easeful interactions revolve. As trojan links to the Internet meme Goatse.cx [19] showed, the merriment of a practical joke can be a hair's breadth away from the abuse of trust.

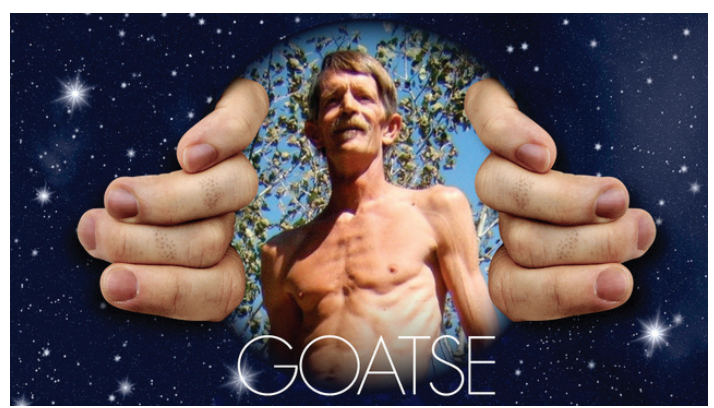

Figure 5: Montage inspired by the Goatse Internet meme. Digital montage. n.d. Finding Goatse: The Mystery Man Behind the Most Disturbing Internet Meme in History. gawker.com. Web. 29 Sep. 2013.

\section{FETISH}

As social media has refreshed the status of the Internet troll, the nuanced subterfuge of social engineering, of spreading Fear, Uncertainty and Doubt, appears diminished. Flames, defamation and libel have become the norm. The specialized rules of email etiquette have evaporated. In the merging of media, products and social interaction, trolling itself has gone viral; selfvalidating intercourse has been upstaged by social-media-sanctioning broadcast-media discourse. In legal proceedings (as with subterfuge against enemy combatants, and leaders of states), a game of cat and mouse is being played; in litigation, plaintiffs become complicit in a mystifying data hide-and-seek, where bytes are transferred, as if seamlessly across frontiers, until reaching new data housing facilities (fortresses of this age).

Other means of outwitting covetous censorial desires have been conceived. Perhaps none has scored higher than the self-mutilation of computers enacted by The Guardian newspaper in response to a threatened injunction on reporting leaked NSA data:
in a deserted basement of The
Guardian's King's Cross offices, a senior editor and a Guardian computer expert used angle grinders and other tools to pulverise the hard drives and memory chips on which the encrypted files had been stored. As they worked they were watched by technicians from Government Communications Headquarters (GCHQ) who took notes and photographs... (Borger)

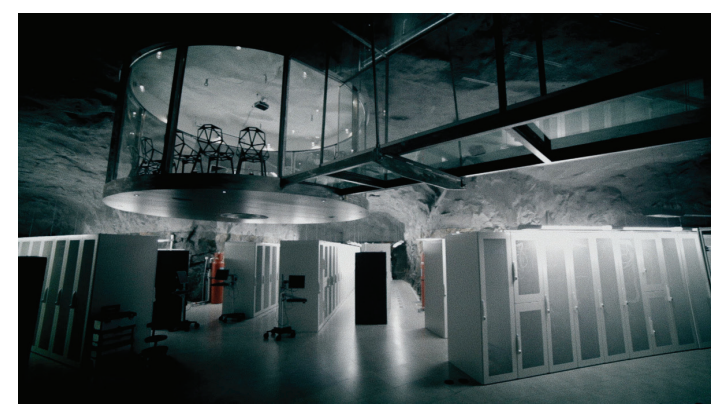

Figure 6: Shockblast underground data centre. Photograph. n.d. TPB:AFK watch.tpbafk.tv. Web. 29 Sep. 2013. 


\section{OBJECTIFICATION}

The fixation on data and hardware objects; the advance of our litigious cultures; these elements may contribute to conditions in which bullying can be blended into human interactions. As much as hardware and new platforms may enable discourse, they also become the sites for abuse, where differences between trolling and harassment easily merge: In the UK, during 2013, a number of women in the public eye (among them MPs, campaigners and journalists) became the target of insults and threats intended to silence their contribution to public debates. Often these communications were sent through Twitter. In what was possibly the most high profile case, the abuse followed a successful campaign to have the Bank of England print a female historical figure on its banknotes. [20] Online, the equivocal status of networks is further evident where derogatory, selfaggrandising 'trash-talk' between computer game players[21] turns to harassment and 'the gamification of misogyny' (Lewis). In the competition for kudos, questions about the liberating potential of the Internet abound.

\section{DISAPPEARANCE}

Such identity fetishism promises certainty in a moment of profound uncertainty, and harks back to a time in which physical media trash appeared more present than today; it is a moment where, in many ways, absence may be more desirable than presence. The contradiction in interfaces is that in the moment they renounce claims on materiality, they may still expose us to physical threat (whether actual or perceived). Accordingly, Internet trolls revel in their ability to circumvent blocks, hide or adopt new identities and to label messages in ways that reach targets indirectly.[22] The collision between anonymity and free speech makes clear why for some, disappearance is preferable to the advice, 'do not feed the trolls'. In examples of this, activist Caroline Criado-Perez was driven to delete her twitter account after she received a series of rape threats online (Topping); in 2012, as a consequence of bullying which began online and followed her during several years and different schools, the Canadian teenager Amanda Todd committed suicide (Amanda Todd's Death).

\section{Afterglow}

\section{VERSIONING AS METHOD}

In a broad sense, and in different domains, we are now seeing truth and responsibility increasingly under review; In the widening push to deliver up to the minute news, the sources and verifiability of content are an ever more present consideration (think of the Yes Men's Bhopal anniversary action [23]). Concern for information ethics, in public and private domains, means questions of accountability and trust (the veracity of versions) gain significant attention: The extended reach of media is changing the act of reflection; propagating images, collectivizing values. In the networked era, reduction is going global.

Away from the context of news and entertainment media, images also circulate in obscure ways. In the apparatus' of political, social and economic assemblages, images now appear as agents. They are the subjects of viral exchange on social networks and potentially convey malicious executable computer code - this is no longer speculation (Tung). Intrinsic to this agency, in the dissemination of images, is the creation of copies. These copies are the multiplying trash by-products of networks' movements, "diverse objects brought together in particular relations, such as the detritus of everyday life unearthed in an archaeological dig" (Wise 78). Whilst networked computer assemblages 
generate data in ever greater volume, other assemblages constitute networks in a similar vein: in digital cameras images are made in multiple versions, modelling 'pipeline' work flows and invoking the trope of 'relation'; Images constitute networks where value, exchange, and mutability are implicit. They are pixel-assemblages to be seen as networks in and of themselves.

Relating Michael Callon's work on the 'performativity of networks', lain Hardie and Donald Mackenzie write,

For Callon, an actor 'is made up of human bodies but also of prostheses, tools, equipment, technical devices, algorithms etc'. - in other words is made up of an agencement. The notion... involves a deliberate word-play. Agencer is to arrange or to fit together: in one sense, un agencement is thus an assemblage... The other side of the word-play... is agence, agency. (Hardie and Mackenzie 58)

We can envisage networks as aggregated versions, sites of recursion and reflexivity, in which circular relations establish the inter-relation of medium and method.

\section{Post-irony for a post-digital age}

The activities of comment trolls and websites such as ask.fm demonstrate other ways in which the Internet has become a machine for reflectivity: Interactions dominated by glib and clever epithets invariably promote self-image over self-knowledge (though with notable exceptions[24]). Rhetoric turns the joke upon those who have missed the joke. These episodes thrive on lack of understanding and the connoisseur's appreciation of the unspoken: The joke is ruined if you spell it out (Harman).

However, the targets of abuse are standing up against such misrepresentation. Their narratives are the alternative versions filling gaps in communication. In this way identities are re-presented; self-images are recomposed. Projects such as unslut [25] have this same end, of allowing individuals to positively re-enact negative stories.[26] Intimate reflections like these are in contrast to celebrity relationships lived through media and social media, where the open-ended repetition of text and image insinuates another kind of performance.[27] In a quieter way, self-representation is also self-creation:

my proliferation of selfies is a small way of fighting back. The more I look at myself (in a mirror or in pictures), the easier it becomes to accept that this is really me, and this is my skin... I feel that the more pictures I post of me, sure l'm putting myself out there to be judged, but I am also adding to images out there (in the minds of friends and strangers alike) of who I am. (Stuficionado)

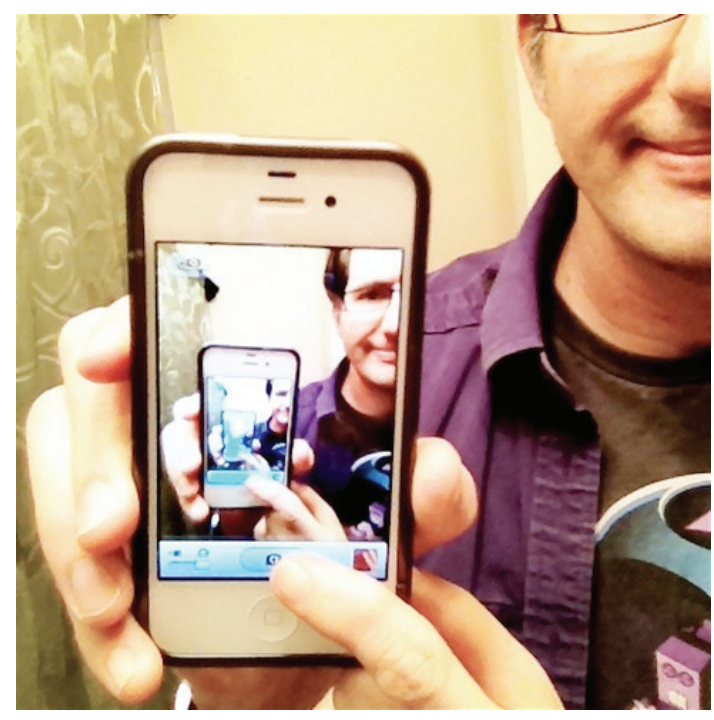

Figure 7: Mekhitarian, Vahram. "Recursive Cell." Photograph. 2013. File:Recursive Cell.jpg Wikimedia Commons. Web. 10 Jan. 2014. 
As images and self-images re-instate a sense of place, absent themselves from rhetoric and generate their own associations, they obtain a peculiar sense of agency. They are re-entering the world as prosaic reminders of the real - hermetic emblems of an already present, post-ironic post-digital age:

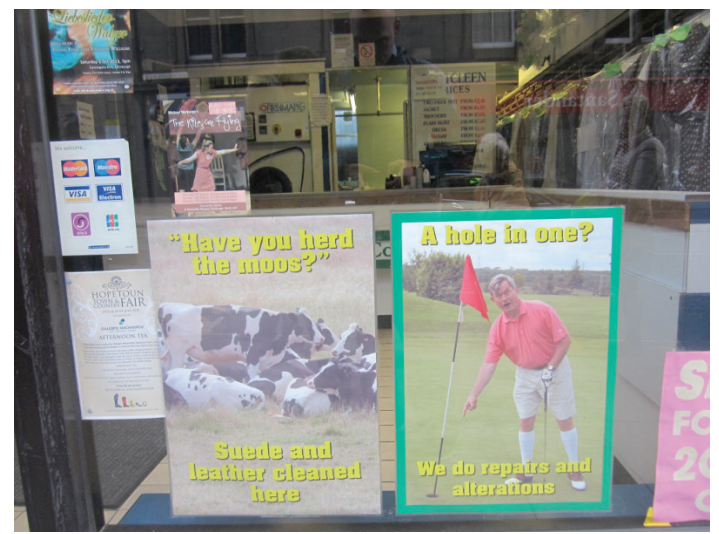

Figure 8: Advertisement posters for a dry cleaner's shop, apparently inspired by Internet memes. Edinburgh, 2013. Photograph by author.

\section{Notes}

[1] http://www.ohchr.org/en/

NewsEvents/Pages/DisplayNews. aspx?NewsID=13706\&LangID=E.

[2] For an explanation see http://www. housing.org.uk/policy/welfare-reform/ bedroom-tax.

[3] http://www.dailymail.co.uk/news/article-2418194/Outrage-loopy-UN-inspectorlectures-Britain-Shes-violent-slum-riddenBrazil-attacks-housing-human-rights.html.

[4] http://www.dailymail.co.uk/news/article-2418993/Trial-collapses-men-accusedrape-police-discover-new-evidence-oldTwitter-account-14.html.

[5] http://www.archive.org/web/web.php.

[6] http://www.seppukoo.com.

[7] http://www.git-scm.com.

[8] http://www.git-scm.com/docs/git-blame.

[9] http://www.spring-alpha.org/svs/.

[10] http://www.situatedtechnologies. net/?q=node/85.

[11] https://www.github.com/explore.

[12] http://www.debian.org/social_contract.

[13] http://www.blogs.technet.com/b/microsoft_on_the_issues/archive/2013/08/30/ standing-together-for-greater-transparency. aspx.

[14] http://www.opgraffiti.deviantart.com/ gallery/. 
[15] http://www.nms.ac.uk/highlights/ objects_in_focus/cybraphon.aspx.

[16] http://www.en.wikipedia.org/wiki/ Wikipedia:GLAM/NLS.

[17] http://www.bbc.co.uk/news/ technology-24001692.

[18] http://www.watch.tpbafk.tv/.

[19] http://www.gawker.com/5899787/ finding-goatse-the-mystery-man-behind-themost-disturbing-internet-meme-in-history.

[20] http://www.thewomensroom.org.uk/ banknotes.

[21] For examples of trash-talk in online gaming see: http://www.kotaku.com/ the-problem-with-trash-talk-707113214.

[22] "online abusers continued to find "new and imaginative ways" to contact her, through her blog". See http://www. theguardian.com/uk-news/2013/sep/03/ caroline-criado-perez-rape-threats-continue.

[23] http://www.museumofhoaxes.com/hoax/archive/permalink/ the_yes_mens_bhopal_hoax.

[24] http://www.theguardian.com/technology/2013/sep/09/ jake-davis-topiary-lulzsec-answers.

[25] http://www.unslutproject.com/

[26] "I felt like the chat box could see me through the computer screen." See: http:// www.theguardian.com/society/2013/sep/21/ unslut-project-against-sexual-bullying.
[27] See remarks about Kayne West and Kim Kardashian's relationship: http://www. theguardian.com/lifeandstyle/2013/oct/27/ instagram-selfie-reveal-kim-kardashiantweet.

\section{Works cited}

"Amanda Todd's Death." knowyourmeme. com. Cheezburger Inc., n.d. Web. 5 Dec. 2013.

BBC News. "High Court: Sally Bercow's Lord McAlpine Tweet Was Libel." bbc.co.uk. British Broadcasting Corporation, 24 May 2013. Web. 29 Nov. 2013.

Borger, Julian. "NSA files: Why the Guardian in London Destroyed Hard Drives of Leaked Files." theguardian.com. Guardian News and Media Limited, 20 Aug. 2013. Web. 29 Sept. 2013.

Brown, Barrett in "How Hackers Changed the World - We Are Legion." Storyville. BBC, HD. 12 Mar. 2013. Television.

Cunningham, Ward quoted in many2many. "Ward Cunningham on the Crucible of Creativity." corante.com. Corante, 17 Oct. 2005. Web. 5 Dec. 2013.

Domscheit-Berg, Daniel with Klopp, Tina. Inside WikiLeaks. Trans. Chase, Jefferson. London: Jonathan Cape, 2012. Print.

Davis, David. "We Can't Let 12 Good Men and True Be Undone by the Internet." theguardian.com. Guardian News and Media Limited, 19 Jun. 2011. Web. 5 Dec. 2013. 
De Landa, Manuel. New Philosophy of Society: Assemblage Theory and Social Complexity. London: Continuum, 2006. Print.

Formamat. "About - Formamat." formamat. com. n.p., n.d. Web. 29 Sept. 2013.

Flusser, Vilem. Into the Universe of Technical Images. Minneapolis: University of Minnesota Press, 2011. Print.

Fuller, Matthew and Haque, Usman. "Urban Versioning System 1.0" Situated Technologies Pamphlets 2. The Architectural League of New York, 2008. PDF.

Gentleman, Amelia. “UN Housing Expert's Call to Axe Bedroom Tax 'A Disgrace'Senior Tory." theguardian.com. Guardian News and Media Limited, Sep. 2013. Web. 29 Sep. 2013.

Hardie, lain and Mackenzie, Donald. "Assembling an Economic Actor: The Agencement of a Hedge Fund." The Sociological Review 55.1 (2007): 57-80. Print.

Harman, Graham. Weird Realism Lovecraft and Philosophy. Alresford: Zero Books, 2012. Print.

Heath Cull, Daniel. The Ethics of Emerging Media. Information, Social Norms, and New Media Technology. London: Bloomsbury Publishing, 2011. Print.

Jarvis, Jeff. "I fear the chilling effect of NSA surveillance on the open internet." theguardian.com. Guardian News and Media Limited, 17 Jun. 2013. Web. 29 Sep. 2013.
Kelty, Christopher. Two Bits: The Cultural Significance of Free Software. Durham NC: Duke University Press, 2008. Print.

Lewis, Helen. "Yes, It's Misogynistic and Violent, but I Still Admire Grand Theft Auto." theguardian.com. Guardian News and Media Limited, 21 Sep. 2013. Web. 29 Sep. 2013.

Lovink, Geert. Zero Comments: Blogging and Critical Internet Culture. Abingdon and New York: Routledge, 2008. Print.

Nelson, Ted. Computer Lib/Dream Machine. Self-published, 1974. Print.

Nissenbaum, Helen. Privacy in Context: Technology, Policy, and the Integrity of Social Life. Stanford: Stanford Law Books, 2011. Print.

Shaikh, Maha. "Mutability and Becoming: Materializing of Public Sector Adoption of Open Source Software." Shaping the Future of ICT Research. Methods and Approaches. 389 (2013): 123-140. Print.

Sifry, Micah L. WikiLeaks and the Age of Transparency. New Haven: Yale University Press, 2011. Print.

Stuficionado. "Just Shoot Me". stuficionado. net. n.p., n.d. Web. 5 Dec. 2013.

Topping, Alexandra. "Caroline Criado-Perez Deletes Twitter Account After New Rape Threats". theguardian.com. Guardian News and Media Limited, 6 Sep 2013. Web. 5 Dec. 2013.

Tung, Liam. "BlackBerry Enterprise Server Malicious TIFF Attack Discovered." zdnet. com. CBS Interactive, 19 Feb. 2013. Web. 5 Dec. 2013. 
Turner, Fred. From Counterculture to Cyberculture: Stewart Brand, the Whole Earth Network, and the Rise of Digital Utopianism. University of Chicago Press: Chicago, 2005. Print.

Wise, J. MacGregor. "Assemblages".

Gilles Deleuze: Key Concepts. Ed. Stivale, Charles J. Chesham: Acumen, 2005. 77-87.

Print. 